POEM

\title{
William Carlos Williams circumcises Ernest Hemingway's first son
}

Previously published at www.cmaj.ca

So I said, sure, and why not? The next sweet morning of Paris drunk with the warm scent

of rain on gravel

in Luxembourg Gardens

and my head as big as a bucket

a - shall we say - after-effect

of the prizefights we went to the night before

the four of us

roiled in the grit and sawdust and sweat - Kill him!

Kill the bastard! - Flossie cried.

So I picked up my leather kit and went back to Hem's flat

laid the kid on the kitchen table and lopped off his foreskin

- his teeny binky, Hadley cried which in those days

was what you did. At the sight of Bumby's blood, bloody big Hem

standing at the side of the table holding the kid's head

collapsed

a sack of potatoes, a tin of lard fainted ker-boom

dead to the world. After the days in Paris

they kept asking me how could I go back

to the pale complexities of practice?

To the grime

of Rutherford's bodies?

The drum of routine -

I think of Hem on the floor at the first drop of his son's blood.

What a man! It isn't anything

I could explain, I tell them. Just call it making a living.

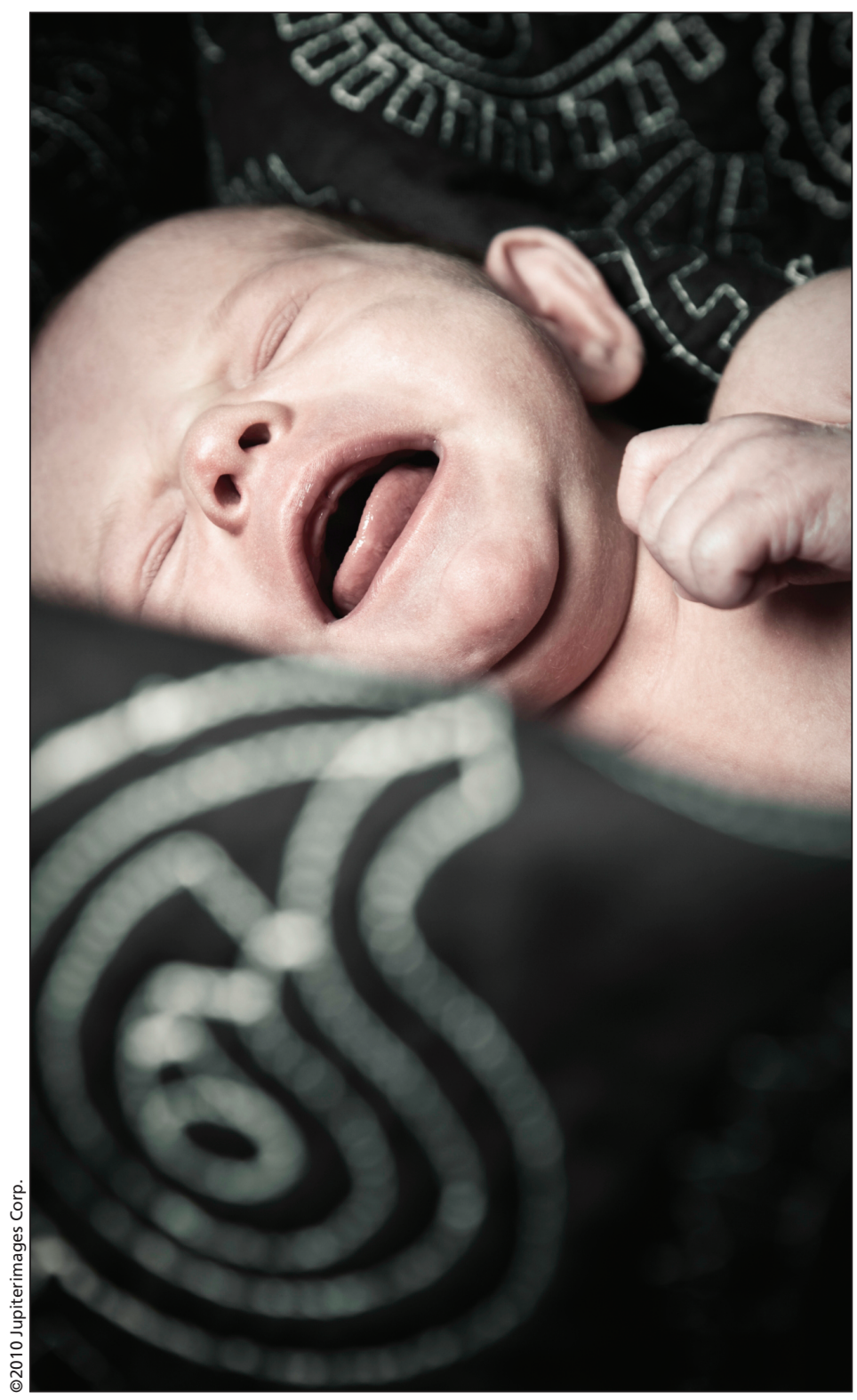

Jack Coulehan MD MPH

Senior fellow

Center for Medical Humanities,

Compassionate Care and Bioethics

Stony Brook University

Setauket, USA

Jack Coulehan's most recent collection of poems is Medicine Stone (Fithian Press; 2002). 